\title{
TIEMPO HISTÓRICO, REDENCIÓN Y OPRIMIDOS EN BENJAMIN APORTES PARA LA PRAXIS POLÍTICO-CULTURAL
}

\author{
Alejandro Casas
}

\section{Resumen}

Nos proponemos recuperar algunos aportes teóricos de la obra de Walter Benjamin, con el trasfondo de subsidiar búsquedas interpretativas para la comprensión de las transformaciones societales y la praxis político-cultural de las clases oprimidas, los sujetos colectivos y los proyectos transformadores en nuestra América. Tomando en consideración la singular comprensión y análisis del tiempo histórico que permea toda la obra de Benjamin, nos centraremos en algunas interpelaciones de su última etapa, de corte más histórico-político y de un marxismo heterodoxo, para detenernos luego en algunas categorías e imágenes dialécticas fundamentales y entrelazadas entre sí. Para ello abordaremos algunos conceptos claves, tales como los de tiempo histórico, rememoración, redención, "tiempo-ahora”, oprimidos.

Palabras clave: Benjamin, tiempo histórico, rememoración, redención, tiempo-ahora, oprimidos.

\section{Abstract}

Historical time, redemption and oppressed in Benjamin. Contributions to the political-cultural praxis

We intend to recover some theoretical contributions from the work of Walter Benjamin, with the background of subsidizing interpretive research for the understanding of societal transformations and the political-cultural praxis of the oppressed classes, collective subjects and transformative projects in our America. Taking into consideration the unique understanding and analysis of the historical time that permeates all Benjamin's work, we will focus on some questions of his last stage, of a more historical-political nature and of a heterodox marxism, and then stop at some categories and dialectical images that are fundamental and intertwined. For this we will address some key concepts, such as historical time, remembrance, redemption, "time now", oppressed.

Keywords: Benjamin, historical time, remembrance, redemption, "time-now", oppressed.

\footnotetext{
Alejandro Casas: Doctor y magíster en Servicio Social por la Universidad Federal de Río de Janeiro. Asistente social universitario por la Universidad de la República. Posdoctorado con el profesor Michael Löwy (Centre D'Études en Sciences Sociales du Religieux-École des Hautes Études en Sciences Sociales-Centre National de la Recherche Scientifique). Profesor titular del Departamento de Trabajo Social, Facultad de Ciencias Sociales (DTS-FCS-UDELAR). Coordinador del Proyecto Integral Sujetos Colectivos y Organización Popular, de la Licenciatura en Trabajo Social (DTS-FCS-UDELAR). Coordinador de la Maestría en Trabajo Social. ORCID iD: 0000-0002-6784-9821

Email: alejandro.casas@cienciassociales.edu.uy
} 


\section{Introducción}

Mucho se ha escrito sobre la obra de Walter Benjamin (1892-1940), aun con interpretaciones muchas veces divergentes sobre su alcance y sus contribuciones, lo que continúa, sin duda, en los tiempos actuales. ${ }^{1}$ Se trata de una obra fermental, heterodoxa, creativa, abierta y difícilmente clasificable.

Entendemos que la obra de Benjamin convoca también a dialogar con los procesos sociopolíticos y culturales contemporáneos en nuestra América, ${ }^{2}$ con los movimientos sociopolíticos y sus procesos de (auto)formación, entre otras dimensiones. Ciertamente si tomamos en cuenta el ámbito de enunciación de su obra, podemos decir que este está fuertemente pautado por las culturas alemana y francesa - en todo caso, europea- y asociado al mesianismo judío, al romanticismo revolucionario y a utopías libertarias. En ese sentido, su perspectiva teórica es claramente crítica y emancipatoria, posicionándose desde la perspectiva de los oprimidos, los dominados, los explotados, las "víctimas" o los vencidos de la historia. De esta forma, su obra, de importante sofisticación teórica, mantiene nexos significativos con una intencionalidad política, en el marco de lo que podríamos catalogar como un marxismo heterodoxo. ${ }^{3} \mathrm{Y}$ entendemos que ello tiene muchas potencialidades

1 Al respecto pueden consultarse los siguientes trabajos, entre otros: para las biografías intelectuales Susan Buck-Morss (1995, p. 22) sugiere, entre otras, las de Wolin (1982) y Witte (1985); para el caso francés Löwy (2005, p. 14) subraya los análisis de Bensaïd (1997 y 2010), Mosès (2006), Münster (1996) y la brasileño-francesa Gagnebin (2011); indicamos también a Löwy $(2005,2010$ y 2016) y Abensour $(2013,2016)$. Puede consultarse a los italianos Traverso (2018) o Agamben (2004), a la anglosajona Buck-Morss (1995, 2014), al alemán-israelí Scholem $(2003,2007)$, a los alemanes Hannah Arendt (2016), Tiedemann (2016) o Adorno (1995), y a Wohlfarth (2015). Entre los latinoamericanos, los mexicanos Esther Cohen (2015) y Bolívar Echeverría (2010), los brasileños Konder (1999) y Coelho (2014), los argentinos Dussel (2015) y Vedda (2008) y el alemán-costarricense Hinkelammert (2007, 2013).

2 Utilizamos aquí el concepto y la imagen acuñados por José Martí en su famoso ensayo Nuestra América, de 1891 (1980).

3 Es sabida la influencia que provoca la revolución rusa en su pensamiento, al mismo tiempo que la lectura de Historia y conciencia de clase de Lukács, a partir de 1924, o de Karl Korsch, o su simpatía por algunas tesis de Blanqui o Trotsky (Löwy, 2005, p. 31). Aunque ya su viaje en 1926 a la ex Unión de Repúblicas Socialistas Soviéticas supuso para él una gran decepción que registró en su diario y en sus conversaciones con Brecht en 1938 (Traverso, 2018, p. 211). En este sentido, hay una singular interpretación también del materialismo histórico en Benjamin, más cercana a la "filosofía de la praxis" o a perspectivas heterodoxas, pero también en las referencias a los debates de la Escuela de Fráncfort, con Adorno y Horkheimer sobre todo (no exentos de polémicas), la obra de Bloch, de Buber o de Rosenzweig, al psicoanálisis o a perspectivas más vinculadas a la producción literaria o estética, como en el caso de las obras de Goethe, Kafka, Proust, Baudelaire o de Brecht, o de algunos autores surrealistas, como Aragón, Breton, etcétera. 
para pensar la modernidad latinoamericana, los imaginarios utópicos y las luchas sociales que la transversalizan. Aunque aquí no abordaremos dichas contribuciones por una cuestión de espacio, esperamos que la lectura del trabajo aporte y motive algunas pistas para continuar en esa senda en trabajos posteriores, dejando planteadas algunas preguntas de investigación en las consideraciones finales. ${ }^{4}$

Siguiendo las importantes contribuciones de un destacado especialista en la obra benjaminiana como Stéphane Mosès (2006), podemos indicar la existencia de distintos momentos o énfasis en su trayectoria: un primer período marcado más por influencias teológicas, un segundo más por preocupaciones estéticas y un tercero más claramente influenciado por el marxismo y por preocupaciones politicas. Sin embargo, ello no obsta a que pueda hablarse de una importante continuidad a lo largo de su obra, donde estas influencias pasan a estar en íntima relación y diálogo, al mismo tiempo que el pasaje de un énfasis a otro no supone abandonar, sino, en todo caso, resignificar los aportes de las etapas anteriores. ${ }^{5}$

Nos proponemos entonces recuperar y problematizar aquí algunos aportes teóricos de la obra de Walter Benjamin. Tomando en consideración la singular comprensión y análisis del tiempo histórico que permea toda su obra, nos centraremos en algunas interpelaciones de su última etapa, de corte más histórico-político-cultural y pautadas por la elaboración en el marco de un marxismo heterodoxo y libertario, para detenernos luego en algunas categorías e "imágenes dialécticas" fundamentales y entrelazadas entre sí.

En este sentido, abordaremos algunos conceptos claves, como ser los de tiempo histórico, rememoración, redención, tiempo-ahora y (clases y grupos) oprimidos, indicando también, más lateralmente, otros conceptos y perspectivas que emergen del trabajo benjaminiano.

Nos referiremos, en particular, a algunas de sus obras tardías, particularmente sus tesis en Sobre el concepto de historia, de 1940 (2006b),

4 Se trata, por otra parte, de una tarea que reconoce ya múltiples contribuciones y desarrollos, algunos indicados en la nota 1. Este artículo, que surge de la colaboración entre investigadores de la región y remite a la realización del Seminario Movimientos Sociales, Praxis Pedagógicas y Educación, del 2018, también encuentra una motivación académica en la realización de estudios posdoctorales en 2018 en París, Francia, bajo la orientación del profesor Michael Löwy. En ese sentido, venimos trabajando con la obra de Benjamin y sus concepciones sobre el tiempo histórico y las utopías, así como con la recepción y el diálogo con su obra desde la perspectiva del pensador alemán costarricense Franz Hinkelammert, entre otras líneas de profundización del legado benjaminiano. En ese marco cobra sentido también el abordaje de diversas interpelaciones de su obra para comprender las luchas sociales en el contexto de las formaciones sociales latinoamericanas contemporáneas y en nuestro tiempo actual.

5 Ver al respecto, por ejemplo, la articulación al estilo de una "afinidad electiva", entre materialismo histórico y teología, que propone en su famosa Tesis I de Sobre el concepto de historia (Benjamin, 2006, p. 305). 
junto con sus "Notas preparatorias" $(2005),{ }^{6}$ que entendemos que son claramente reflejos de su obra más madura y política, entre otros trabajos. Haremos referencia a escritos anteriores de forma muy parcial o puntual. Omitiremos muchos detalles biográficos y de contexto histórico que son, sin duda, significativos para valorar mejor su obra. Nos apoyaremos, sí, en distintas lecturas críticas realizadas sobre una obra que, reiteramos, reconocemos como de altísima sofisticación y complejidad, inclusive con muchas zonas oscuras y opacas de muy difícil interpretación para nosotros. ${ }^{7}$ Enfatizaremos aquí en el Benjamin más político y marxista, aun teniendo presente las indicaciones de Mosès sobre su indisociabilidad con el Benjamin más teológico y el orientado hacia los estudios estéticos o de la cultura.

\section{Sobre su concepción del tiempo histórico y la rememoración}

Podemos ver una característica saliente y singular de Benjamin, a lo largo de toda su vida, en su concepción del tiempo histórico — compartida con autores como, entre otros, Gershom Scholem (su íntimo amigo) y Franz Rosenzweig (cuya obra La estrella de la redención [1982] Benjamin admiraba)_, que se corresponde con una dimensión radicalmente diferente de la conciencia histórica hegemónica, remitiendo directamente a la llamada tradición del mesianismo judio y que se traduce en una esperanza histórica muy singular.

Dichas marcas del mesianismo judío son innegables en Benjamin. Este tiene en nuestro autor un carácter herético en relación con sus tendencias dominantes, en un sentido similar al que lo será su propia concepción del marxismo. Como indica el historiador italiano Enzo Traverso, Benjamin no pensaba el judaísmo en términos de una identidad nacional ("el sionismo le

6 Cabe indicar que, siempre que fue posible, trabajamos con las obras de Benjamin en castellano, editadas por Tiedeman y Schweppenhaüser con colaboración de Adorno y Scholem (2006a y 2006b, entre otras). Haremos algunas referencias muy laterales al Libro de los Pasajes, que corresponde a la traducción al castellano de la edición de Tiedemann, en Benjamin (2016). Las notas preparatorias las tomamos del texto preparado por Bolívar Echeverría (Benjamin, 2005). En el caso de las referencias a las tesis de Sobre el concepto de historia (en Obras, 2006) indicaremos el número de la tesis respectiva. Somos conscientes de que, como indica uno de los mayores editores de la obra de Benjamin, Rolf Tiedemann, hay una relación indisoluble entre varios de los últimos trabajos de Benjamin. Dice al respecto, por ejemplo, sobre el Libro de los Pasajes, que su lectura "tendría por eso que incluir el ensayo sobre la obra de arte [en la época de su reproductibilidad técnica, de 1935-1936], los textos dedicados a Baudelaire [entre 1937-1939] y las tesis Sobre el concepto de historia [1940], teniéndolos siempre presentes aun cuando sean completamente independientes y representen, bien un simple preludio del Libro de los Pasajes, bien escritos desgajados de él" (Tiedemann, 2016, p. 10). Al mismo tiempo, otro texto clave y emparentado con las tesis es su ensayo sobre Fuchs, de 1937. En los casos en los que se trabajó sobre textos en francés o portugués, las traducciones incluidas en este artículo son de nuestra autoría.

$7 \quad$ Scholem lo destaca especialmente: "Benjamin es un autor difícil. Sus grandes trabajos exigen del lector un extraordinario grado de concentración. [...] Al mismo tiempo, se hallan escritos por lo general en una prosa perfecta, de la que irradia un extraño poder" (Scholem, 2003, p. 16). 
parecía una versión caricatural de la ideología del nacionalismo racial"), ya que su vocación era de tipo "diaspórica". Su destino era indisociable del de Europa. Pero, por otra parte, "su mesianismo no tenía nada de la espera pasiva de una intervención divina" o de alguna fuerza venida del exterior. Benjamin no creía en la espera pasiva de ningún mesías, sino que entendía que había que "provocarlo y que esta interrupción del curso del mundo debía suceder como un acto revolucionario de los hombres" (Traverso, 2018, pp. 211-212).

Para Benjamin, entonces, el pasado no es "letra muerta" o mera tradición ya fenecida, sino que mantiene relaciones y vinculaciones muy especiales con el presente y el futuro. Hay, en todo caso, una complejísima dialéctica entre pasado, presente y futuro en el autor, que dice sobre su particular comprensión de la historia. Como indica Sthéphane Mosès (2006), la concepción histórica de Benjamin se opone al menos a dos perspectivas sobre la historia. Por un lado, a aquella del tiempo cíclico, del "eterno retorno" de Nietzsche, que aparece también en Auguste Blanqui, en La eternidad por los astros (2002), con la que Benjamin dialoga.

Pero, al mismo tiempo, la concepción histórica de Benjamin se opone a la idea de progreso, a la idea de un tiempo lineal, acumulativo, "vacío", que se corresponde para él con el espacio del mito ${ }^{8}$ En este sentido, un concepto central de Benjamin es, confrontando con estas visiones, el del tiempoahora o jetzeit (sobre el que volveremos luego). Este rompe la continuidad de la historia. A diferencia de las tesis de Nietzsche, lo que ha sido no es irrevocable, puede ser redimido. Lo que en el pasado ha sido abandonado, perdido, derrotado, olvidado, lo que no ha podido ser realizado, puede ser recuperado y reparado en el presente. Esta posibilidad de "salvar" el pasado es tanto una tarea teórica como política, corresponde tanto al historiador como a aquellos que hacen la historia. El porvenir, en lugar de repetir mecánicamente lo ya dado, se abre de esta manera a lo nuevo, a la novedad histórica, por medio de la "imaginación, la utopía o la acción anticipadora" (Mosès, 2006, p. 249). La "somnolencia", el sueño en el que vive el siglo XIX (y que Benjamin investigará en su proyecto del Libro de los Pasajes, 2016) genera ineptitud para crear lo realmente nuevo.

Para Benjamin la "historia de los oprimidos es una historia discontinua", mientras que "la continuidad es aquella de los opresores" (Benjamin apud Mosès, 2006, p. 218). Pero para él no se trata tanto de "reencontrar" el pasado, sino más bien de "salvarlo", como en la obra de Proust, darle una nueva "actualidad" en el seno del presente (Mosès, 2006, p. 211). El pasado puede ser redimido. Pero tampoco se trata de conmemorarlo, convertirlo en objeto de museo, lo que sería una nueva forma de "conformismo" (Mosès, 2006, p. 219).

8 Su interpretación del cuadro Angelus Novus, de Paul Klee, que poseía Benjamin, es la alegoría que él identifica con esa perspectiva "incontenible" de la tempestad del progreso que controla al ángel de la historia hacia un futuro incontrolable (Benjamin, Tesis IX, 2006, p. 310). 
En relación con su concepción del tiempo histórico, la rememoración es una categoría central en Benjamin. Pero no podemos entenderla separada de sus conceptos de redención o de utopía. En las "Notas preparatorias" a Sobre el concepto de historia aparece la siguiente referencia de Benjamin:

"De los que vendrán no pretendemos gratitud por nuestros triunfos, sino rememoración de nuestras derrotas. Eso es consuelo: el consuelo que solo puede haber para quienes ya no tienen esperanza de consuelo." (Benjamin, 2005, p. 53).

Michael Löwy, un especialista en la obra benjaminiana y las tesis de Sobre el concepto de historia, indica que aquí Benjamin se está refiriendo a su propia generación, fuertemente atacada por el nazismo. Pero obviamente su perspectiva tiene un trasfondo que implica a todas las clases oprimidas y vencidas a lo largo de la historia. Ellas se hacen presentes en las luchas actuales, donde actúan en "nombre de generaciones de vencidos" (Benjamin, Tesis XII, 2006a, p. 313), con referencias a Espartaco y Blanqui. Benjamin critica directamente a la socialdemocracia de aquella época, presa de concepciones contaminadas por un marxismo vulgar y evolucionista, por atribuir a la clase trabajadora "el papel de mera redentora de las generaciones futuras. Con ello cortó el tendón donde se apoya la mejor de las fuerzas" (Benjamin, Tesis XII, 2006a, pp. 313-314).

Hay aquí una diferencia incluso con relación a cómo Marx se refería a la relación de las clases revolucionarias con las clases oprimidas y explotadas del pasado, y a la relación con la memoria de las luchas pasadas. Como recuerda Enzo Traverso, en El 18 brumario de Luis Bonaparte (1969), la memoria es evocada como "la tradición de todas las generaciones muertas" que "oprime como una pesadilla el cerebro de las vivas". Pero la revolución moderna dirigida contra el capitalismo, indica Marx, "no puede tomar su poesía en el tiempo pasado, pero solamente en el futuro". Ella debe "dejar a los muertos enterrar a los muertos" y desembarazarse de las "reminiscencias prestadas a la historia universal" para poder proyectarse al futuro (Traverso, 2018, p. 77; Marx, 1969).

Existen otras singularidades muy importantes en el pensamiento de Benjamin, que dicen también sobre su particular comprensión del tiempo histórico, ubicadas en el marco de lo que Löwy (2016) identifica como romanticismo revolucionario (concepto creado por Lukács), que se separa de otras formas conservadoras o incluso reaccionarias del romanticismo.

Löwy identifica después del fin del siglo XIX y hasta el comienzo de los años treinta un nuevo impulso del romanticismo:

“[...] no designa, aquí, un estilo literario o artístico, sino un fenómeno mucho más vasto y profundo: la corriente de nostalgia de las culturas precapitalistas y de crítica cultural de la sociedad industrial/burguesa, 
corriente que se manifiesta tanto en el dominio del arte y de la literatura cuanto en el pensamiento económico, sociológico y político. [...] [El romanticismo revolucionario] es una tendencia en la cual se combinan y se asocian de manera inextricable la nostalgia del pasado capitalista (real o imaginario, cercano o lejano en el tiempo) y el espíritu revolucionario de un porvenir nuevo, la restauración y la utopía." (Löwy, 2016, p. 34).

La incorporación de esta corriente e interpretación permite también tender un puente de comprensión y una relación más estrecha entre las tradiciones del mesianismo judío (en su "interpretación restitucionista/ utópica") y las utopías libertarias o anticapitalistas (incluyendo allí distintas perspectivas socialistas, anarquistas y marxistas), a las que Benjamin adhiere (Löwy, 2016, pp. 34-35).

En síntesis, como indica Löwy, la filosofía de la historia de Benjamin se nutre de tres fuentes muy diferentes: el romanticismo alemán, el mesianismo judío y el marxismo:

"No se trata de una combinación o síntesis 'ecléctica' de esas tres perspectivas (aparentemente) incompatibles, sino de la invención, a partir de ellas, de una nueva concepción, profundamente original.” (Löwy, 2005, p. 17).

Es interesante hacer notar también cuando Benjamin se acerca con decisión al marxismo, a partir de 1924, con la lectura de Historia y conciencia de clase, de Lukács. Es entonces que se vincula de manera afectiva con el comunismo y lo descubre experiencialmente a partir de Asja Lacis. Pero ello no le hace abandonar algunos presupuestos de anteriores concepciones románticas y mesiánicas, en particular su crítica a la idea del progreso, la que penetraba ya y desde hacía mucho tiempo a importantes círculos del marxismo vulgar (Löwy, 1995, p. 22). Sin embargo, no es que Benjamin ya no tuviera en su vida intelectual anterior una preocupación por la emancipación, incluso por la propia revolución, al contrario; en todo caso le faltaba quizás un recurso más directo a la comprensión de la lucha de clases y de otros elementos importantes de la teoría social de Marx, que reincorporará en su perspectiva teórica y de interpretación. Por ejemplo, la figura del fetichismo de la mercancía estará plenamente presente en el proyecto del Libro de los Pasajes.

\section{Sobre las categorías de redención, tiempo-ahora y los oprimidos}

Otra referencia muy clara a la relación entre las generaciones pasadas y las presentes es la que Benjamin hace en la Tesis II, esta vez en referencia al concepto de redención:

"El pasado comporta un índice secreto por el cual se remite a la redención.

[...] ¿No existe en las voces a que prestamos oído un eco de las ahora 
enmudecidas? Si es así, hay entonces una cita secreta entre las generaciones pasadas y la nuestra. Y sin duda entonces hemos sido esperados en la tierra. A nosotros entonces, como a cualquier otra generación anterior, se nos habrá dotado de una débil fuerza mesiánica a la que el pasado posee un derecho. Ese derecho no cabe despacharlo a un bajo precio. El materialista histórico lo sabe.” (Benjamin, Tesis II, 2006a, p. 306).

Según Löwy, este concepto de redención (Erlösung), que seguramente Benjamin extrajo del libro de Rosenzweig, tiene un doble significado. Primero en la esfera del individuo: allí la felicidad personal presupone la redención de su propio pasado, "la realización de lo que podría haber sido pero no fue". En segundo lugar, con una dimensión más colectiva, en una variante incluida en el Libro de los Pasajes, "presupone la reparación del abandono $[\ldots]$ y de la desolación [...] del pasado. La redención del pasado es simplemente esa realización y esa reparación, de acuerdo con la imagen de felicidad de cada individuo y cada generación" (Löwy, 2005, p. 48). En cualquier caso lo interesante es que la redención está directamente vinculada con el pasado y con la historia de las generaciones anteriores, ${ }^{9}$ pero incluye necesariamente también una novedad histórica abierta al futuro, asociada a la realización de potencialidades negadas en el pasado y reparadas en una sociedad emancipada. Como indica Löwy, se trata de una redención entendida estrechamente en relación con el concepto de "rememoración histórica de las víctimas del pasado".

Otro concepto importante aquí es el de reparación, o tikkoun en hebraico, ${ }^{10}$ del sufrimiento, de la desolación de las generaciones pasadas, $\mathrm{y}$, sobre todo, parece ser el caso de la "realización de los objetivos por los cuales lucharon y no consiguieron alcanzar" (Löwy, 2005, p. 51). Se trata de una tarea enteramente humana e histórica, de carácter revolucionario. Esto, dicho sea de paso, será muy importante para pensar las luchas sociales en América Latina, atravesada históricamente por la conquista, el genocidio, la colonialidad y la dependencia.

Es decir que la redención se articula necesariamente a la rememoración (de las luchas y de las víctimas de la historia), suponiendo, al mismo tiempo, una transformación del presente y una reparación en términos de la lucha por alcanzar aspiraciones y objetivos emancipatorios que fueron en su

9 Como el propio Benjamin lo indica en la Tesis IV de Sobre el concepto de historia: "Pues lo mismo que hay flores que vuelven su corola en dirección al sol, del mismo modo, gracias a un particular heliotropismo de índole secreta, lo sido se afana por volverse hacia el sol que se alza en el cielo de la historia." (Benjamin, 2006, p. 307).

10 En una variante más amplia del concepto de tikkoun el propio Löwy indica que se trata de un concepto polisémico proveniente de la concepción judía kabalística, que significa a la vez "redención (Erlösung), restitución, reparación, reforma, restablecimiento de la armonía perdida" (Löwy, 2016, p. 8). 
momento derrotados. Se trata de un concepto fundamental en la perspectiva de Benjamin, que se refiere también a la idea de salvación, pero que remite incluso más allá del propio concepto de liberación.

Como indica Jeanne Marie Gagnebin, en su interesantísimo abordaje de la obra literaria y política benjaminiana:

"Lo que desean el historiador 'materialista', el crítico y el traductor auténticos, es siempre, en Benjamin, la salvación, esto es, más que la conservación piadosa del pasado y de las obras, más que su preservación, para siempre, en los archivos y en las bibliotecas de memoria. [Ello] no agota el significado de la salvación, más precisamente de la redención (Erlösung) que Benjamin siempre definió igualmente, de manera fundamentalmente anárquica y profundamente teológica, como lo que no es solamente liberación, sino también des-enlace, dis-solución (Er-lösung), lo que pone fin a la historia y las obras, lo que las aniquila y las consume." (Gagnebin, 2011, p. 112).

Esta idea de redención remite también, en términos teológicos, a la idea de un regreso a un "paraíso perdido" (que Benjamin vinculará también a las investigaciones y a su propio trabajo sobre Bachofen y el "comunismo primitivo", de 1935) en términos del tikkoun (en la tradición judaica) o la apocatástasis (en ciertas versiones de la doctrina cristiana ortodoxa), como idea de "salvación final de todas las almas", al mismo tiempo que "el regreso de todas las cosas a su estado original" (Löwy, 2005, pp. 55 y 119).

Desde el punto de vista político, la revolución significa también un regreso a una especie de paraíso perdido, como también lo era en Marx al vincular la idea del comunismo primitivo, a través de distintas mediaciones, con la futura sociedad socialista y comunista. Sin embargo, obviamente, como decíamos, ni Marx ni Benjamin plantean un mero regreso a un estado original. En el caso de Benjamin la revolución es en todo caso un quiebre fundamental de la historia, una interrupción en el cortejo de los vencedores y en el continuum del tiempo de los dominantes. Como indica Gagnebin, incluso la idea de la restauración de un orden original en Benjamin indica necesariamente "el reconocimiento de una pérdida, la recordación de un orden anterior y la fragilidad de ese orden": el concepto de "origen" [que fue analizado en El origen del drama barroco ('Trauerspiel') alemán (2006b)] en Benjamin busca, por lo tanto, más que un proyecto restaurativo ingenuo [...] apertura para el futuro, inacabamiento constitutivo" (Gagnebin, 2011, p. 14).

Para comprender mejor estas posibilidades de la transformación revolucionaria, es necesario ir hacia otro concepto central en la obra benjaminiana, cual es el de tiempo-ahora o jetzeit. 
Al decir del propio Benjamin:

"La historia es objeto de una construcción cuyo lugar no lo configura el tiempo homogéneo y vacío, sino el cargado por el tiempo-ahora" (Tesis XIV); "Así, el tiempo-ahora, en cuanto modelo del mesiánico resume toda la historia de la humanidad en una gigantesca abreviatura, viene a coincidir exactamente con la figura que la historia de la humanidad compone en el universo en su conjunto" (Tesis XVIII); "El historiador que parte de ello deja de permitir que una mera sucesión de datos corra por los dedos al igual que un rosario. Con ello capta la constelación en que se adentró su propia época junto a una anterior que se halla determinada totalmente. Funda así un concepto de presente como el 'tiempo-ahora', ese en el cual se han esparcido astillas del mesiánico.” (apéndice A) (2006a, pp. 315, 317 y 318 ).

Este presente como tiempo-ahora recoge sin dudas los elementos de conceptos e imágenes ya desarrolladas anteriormente, pero es el ámbito central, para la comprensión tanto del tiempo y el presente histórico como de la lucha política propiamente dicha (y revolucionaria) en Benjamin. Como indica Löwy, el "jetzeit resume todos los momentos mesiánicos del pasado, toda la tradición de los oprimidos es concentrada, como una fuerza redentora, en el momento presente, el del historiador o el del revolucionario" (1995, pp. 138-139). Como veíamos, este concepto del tiempo se opone radicalmente al tiempo del progreso, al tiempo vacío, al tiempo de los relojes, al chronos. Se trata de un tiempo aleatorio, imprevisto, abierto a la irrupción de lo nuevo, un tiempo de posibilidades más que de necesidades (Löwy, 1995, p. 141) —recordemos que Benjamin decía que era el tiempo en el que "cada segundo constituía la pequeña puerta por la que el Mesías podía penetrar" (2006a, p. 318)-.

En términos de la lógica de la investigación histórica, aparecen también múltiples referencias de Benjamin a conceptos e imágenes dialécticas ampliamente sugerentes y novedosas. Una de ellas es el concepto de constelación. Como recordábamos en el fragmento de una cita anterior (apéndice A de las Tesis), la constelación para Benjamin supone vincular dos épocas y tiempos históricos aparentemente inconexos entre sí, separados incluso por millares de años. Señala por su parte (en algo que fue ironizado por Marx) el ejemplo de la relación con la Antigua Roma de los revolucionarios jacobinos, que era para Robespierre "un pasado lleno de ese tiempo-ahora que él hacía saltar respecto del continuo de la historia (Tesis XIV, 2006a). Esta imagen remite a la relación entre distintas estrellas, las que, perdidas en la inmensidad del cielo, "reciben un nombre cuando un trazado común las reúne" (Gagnebin, 2011, p. 15).

En ese presente constituido como tiempo-ahora, se esparcen las astillas del tiempo mesiánico, lo que para Löwy significan en Benjamin "los momentos de revuelta, los breves instantes que salvan un momento del pasado y, al mismo 
tiempo, efectúan una interrupción efímera de la continuidad histórica, un quiebre en el núcleo del presente" (Löwy, 2005, p. 140). Esta constelación, al modo de un relámpago, permite conectar fragmentos del pasado con el presente: "la verdadera imagen del pasado pasa súbitamente. El pasado solo cabe retenerlo como imagen que relampaguea de una vez para siempre en el instante de su cognoscibilidad" (Benjamin, Tesis V, 2006a, p. 307). O, en la Tesis VI: "Articular el pasado históricamente no significa reconocerlo 'tal y como propiamente ha sido'. Significa apoderarse de un recuerdo que relampaguea en el instante de un peligro" (Benjamin, Tesis VI, 2006a, p. 307). Aquí las referencias al peligro del fascismo son muy directas, pero esta concepción ataca también las bases de la comprensión hegemónica del marxismo vulgar y de la socialdemocracia de aquel entonces. Son las clases oprimidas y la acción revolucionaria las que pueden hacer estallar el continuo de la historia: "La conciencia de hacer saltar el continuo de la historia es peculiar de las clases revolucionarias en el instante mismo de su acción" (Benjamin, Tesis XV, 2006a, p. 315). Y para ello es fundamental la constelación que conecta también diversas rebeliones y estallidos revolucionarios, históricamente derrotados, con el tiempo de la acción presente. ${ }^{11}$

Hay otros conceptos que serán claves para esta interpretación de la historia y su perspectiva de redención-rememoración-tiempo-ahora, y que expresan una relación, como veíamos, con el concepto de clases oprimidas, vencidas, derrotadas, esclavizadas, víctimas, trabajadoras, entre otros conceptos a los que Benjamin alude permanentemente en las tesis y en otros escritos. Esto está muy relacionado con la cuestión de la lucha político-cultural, como veremos a continuación. Desde el punto de vista del conocimiento histórico, las clases oprimidas y explotadas tienen un lugar privilegiado para Benjamin: "El sujeto del conocimiento histórico es la misma clase oprimida que lucha" (2006a, Tesis XII, p. 313). ${ }^{12}$ Hay, por lo tanto, una claridad en Benjamin para entender la conciencia de clase como producto de la práctica de lucha, no como algo meramente intelectual, sino formando parte de la experiencia activa de la clase trabajadora. Esto acerca su pensamiento al marxismo, entendido como filosofía de la praxis, en la línea del primer Lukács, Korsch, Rosa Luxemburgo, Gramsci, Mariátegui, Che Guevara, entre otros (Löwy, 2005, pp. 108 y ss.).

En este sentido, otro concepto central será el de experiencia auténtica (Erfahrung), en oposición al concepto de vivencia inmediata (Erlebnis) presente en algunos textos tempranos de Benjamin, y que reaparecen en

11 Otro ejemplo mencionado por Löwy es el de Ernst Bloch, cuando vincula las sublevaciones revolucionarias de la Alemania de los años 1919-1921 con la rebelión campesina liderada por Thomas Münzer en el siglo XVI (Löwy, 1995, p.128). Pero los ejemplos podrían ser múltiples y más si lo vemos en la historia moderna de nuestra América.

12 O en otros pasajes de las tesis, esta vez con relación al fascismo: "La tradición de los oprimidos nos enseña que el 'estado de excepción' en que vivimos es sin duda la regla” (Benjamin, Tesis VIII, 2006, p. 309). 
los escritos de Baudelaire de 1936-1938. Esta experiencia auténtica es la experiencia propiamente política, basada en la memoria de una tradición cultural e histórica (Löwy, 2005, pp. 27-28)

Asociada a esto, la cuestión cultural aparecerá como central en todo el trabajo de Benjamin, a quien Susan Buck-Morss califica como "historiador radical de la cultura". En la época burguesa, la transmisión histórica de la cultura se desarrollaba como si sus objetos fueran mercancías para ser vendidas y poseídas, más que experimentadas. Todo valor potencialmente revolucionario permanecía latente (Buck-Morss, 2014, pp. 15-17).

La autora destaca, asimismo, la vinculación político-pedagógica del trabajo de Benjamin:

“[...] como 'dinamita política', estos anticuados productos de la cultura de masas proporcionarían una educación política marxista-revolucionaria a los sujetos históricos de la propia generación de Benjamin, las víctimas más recientes de los soporíferos efectos de la cultura de masas." (Buck-Morss, 1995, p. 20).

Podemos ver en Benjamin una formulación sugestiva de esta concepción crítica de la cultura, los bienes culturales y de la civilización modernocapitalista asociada al legado de los vencedores, en la Tesis VII de Sobre el concepto de historia:

“[...] cuando se pregunta con quién empatiza el historiador historicista. La respuesta resulta inevitable: con el vencedor. Y quienes dominan en cada caso son los herederos de todos aquellos que vencieron alguna vez. Por consiguiente, la empatía con el vencedor resulta en cada caso favorable para el dominador del momento. [...] Y como ha sido siempre la costumbre, el botín de guerra es conducido también en el cortejo triunfal. El nombre que recibe habla de bienes culturales, los mismos que van a encontrar en el materialista histórico un observador que toma distancia. Porque todos los bienes culturales que abarca su mirada, sin excepción, tienen para él una procedencia en la cual no puede pensar sin horror. [...] No hay documento de cultura que no sea a la vez un documento de barbarie. Y así como este no está libre de barbarie, tampoco lo está el proceso de la transmisión a través del cual los unos lo heredan de los otros. Por eso el materialista histórico se aparta de ella en la medida de lo posible. Mira como tarea suya la de cepillar la historia a contrapelo." (Benjamin, Tesis VII, 2005, pp. 22-23, destacados personales). ${ }^{13}$

Esta célebre tesis coloca desafíos tanto para el historiador o intelectual como para el trabajo político, en términos de la exigencia de "cepillar la

13 Recurrimos a esta traducción de Bolívar Echeverría y no a la de las Obras por encontrar algunos errores en esta última. 
historia a contrapelo". En Benjamin, como vimos, ello tiene implicancias teóricas y políticas. Desde el punto de vista teórico, la posibilidad de ir contra la versión oficial del historicismo, contra este cortejo triunfal, es oponiéndole la tradición y la historia de los oprimidos. La continuidad es de los opresores, la discontinuidad, el quiebre, el "olvido" es de la tradición de los oprimidos. La continuidad de los opresores, como indicábamos antes, solo se interrumpe por sublevaciones, revueltas o revoluciones de las clases oprimidas Desde el punto de vista político, la redención/revolución no acontecerá debido al "normal" desarrollo de las contradicciones del capitalismo, sino que es necesario un proceso de lucha activo, que tiene un énfasis político-cultural insoslayable (Löwy, 2005, pp. 71 y ss.).

Por su parte, la oposición entre civilización y barbarie, que tanta influencia tuvo en la Ilustración — pero también en los debates de las élites y clases dominantes en nuestra América durante los siglos XIX y XX-es vista por Benjamin como una especie de falsa oposición. "No hay documento de cultura que no sea a la vez un documento de barbarie". Esto cuestiona también la idea de la existencia de una "alta cultura" como estrictamente ajena a manifestaciones de violencia, explotación y saqueo, o vinculada exclusivamente a cuestiones espirituales o meramente racionales. En ese sentido, asocia la existencia de estos "documentos de barbarie" a "injusticias de clase, de la opresión social y política, de la desigualdad, y porque su transmisión es hecha por masacres y guerras" (Löwy, 2005, p. 79).

Cabe aclarar que, como veíamos, esto no lleva a Benjamin a ser partidario de un "populismo cultural", rechazando las obras de la "alta cultura" o privilegiando exclusivamente el arte o la cultura "popular". Al contrario, estaba convencido de que muchas de ellas "son abierta o secretamente hostiles a la sociedad capitalista; se trata, entonces, de redescubrir los momentos utópicos o subversivos escondidos en la "herencia cultural" (Löwy, 2005, p. 79). Así como su crítica del progreso no es una desvalorización del progreso técnico o económico en sí mismo ${ }^{14}$ también su crítica cultural debe ser entendida como el interés por la "salvaguardia de las formas subversivas y antiburguesas de la cultura, procurando evitar que sean embalsamadas, neutralizadas [...] por el establishment cultural" (Löwy, 2005, p. 80).

\section{Consideraciones finales}

El trabajo de Benjamin, sobre todo en su última etapa, tuvo un claro perfil político-cultural, anclado firmemente en la teoría crítica y en un marxismo

14 Benjamin criticará a la socialdemocracia, que entiende el progreso solo desde el punto de vista del trabajo o de la dominación sobre la naturaleza, pero que no ve los retrocesos sociales que muchas veces supone: "Acepta solo reconocer el progreso en el dominio de la naturaleza, no el retroceso de la sociedad” (Benjamin, 2006, Tesis XI, p. 311). 
heterodoxo, aunque continuó siendo un trabajo fundamentalmente teórico-filosófico. Las categorías e imágenes dialécticas que permean toda su obra van ganando precisión y concreción conceptual y política en este último período, así como otras nuevas se van desarrollando o transformando. Nos referimos aquí a su concepción del tiempo histórico, la rememoración, la redención, el tiempo-ahora, su comprensión de las clases y grupos oprimidos y sus luchas, y también hicimos referencias más secundarias a conceptos/imágenes como el de constelación, su comprensión de la revolución, la experiencia auténtica, su comprensión de la cultura y la praxis político-cultural, entre otros. ${ }^{15}$

Recordemos cómo entendía Benjamin la revolución, lo que pauta también una diferencia con la perspectiva de la filosofía de la historia de Hegel, pero también del propio Marx:

"Marx dice que las revoluciones son la locomotora de la historia mundial. Pero tal vez se trata por completo de algo diferente. Tal vez las revoluciones son el manotazo hacia el freno de emergencia que da el género humano que viaja en ese tren." (Benjamin, 2005, p. 40).

Se trata, como vimos, de entender la revolución como una interrupción (mesiánica) del tiempo de la continuidad de las clases vencedoras y dominantes, que pueda evitar nuevas catástrofes, frenando aquella tempestad incontrolable que arrastraba al ángel de la historia. Como indican Scholem y Löwy, la sociedad sin clases del futuro es síntesis dialéctica a partir de todo el pasado de la humanidad:

"La verdadera historia universal, basada en la rememoración universal de todas las víctimas sin excepción —el equivalente profano de la resurrección de los muertos- solo será posible en la futura sociedad sin clases." (Löwy, 2005, p. 95).

ComosintetizaLöwy,elmarxismode Benjamin puede asísercaracterizado con distintos términos como "mesiánico", de la "imprevisibilidad", de apertura a la historia. Ello supone considerar la posibilidad cierta (aunque no la inevitabilidad) tanto de la catástrofe, por un lado, como de la emergencia de grandes movimientos emancipadores o utópicos, por el otro. El futuro no está escrito ni definido. Contra las esperanzas y un optimismo vacíos que supone

15 De alguna forma, en el monumental proyecto del Libro de los Pasajes (2016) - inconcluso pero de una novedad radical-, en el siglo XIX parisino y francés y anclado en aquellas premisas teórico-políticas, Benjamin pretenderá dar cuenta de un análisis histórico concreto en el que se ponen en juego y en la práctica de la investigación histórica y textual indicaciones metodológicas y premisas del trabajo intelectual que estaban presentes en sus tesis Sobre el concepto de historia y en otros trabajos. 
el concepto de progreso, o contra las perspectivas de un "tiempo cíclico", su marxismo puede ser entendido como atravesado por un momento trágico, que supone la "organización del pesimismo". Hay allí una dimensión utópica frágil (o una "débil fuerza mesiánica", como veíamos según sus propias palabras) que sigue los pasos de la apuesta de Pascal y de Lucien Goldmann, y que "está permeada por una melancolía romántica y por el sentimiento trágico de derrota". Pero no son solamente el futuro y el presente los que permanecen abiertos en Benjamin: también el propio pasado (Löwy, 2005, pp. 149-157). En palabras de Traverso, Benjamin se inserta en una tradición escondida, a la que llama "melancolía de izquierda", que está atravesada por la melancolía de los vencidos (Traverso, 2018), pero que de ninguna forma apela al conformismo o resignación, ni teórico ni político.

Para finalizar, planteamos unas últimas palabras y preguntas sobre algunas de estas categorías benjaminianas, las formaciones sociales latinoamericanas y las luchas populares en nuestra América (considerando a esta como "una unidad en la diversidad”), que funcionan como pistas a explorar.

¿En qué medida las aspiraciones, la memoria, las utopías, las luchas de los vencidos o de las clases y grupos oprimidos a lo largo de nuestra historia moderna - tanto antes de la conquista como en el período colonial, en las luchas por las independencias políticas, en el marco del capitalismo dependiente e imperialista o contra las dictaduras de seguridad nacional o los modelos neoliberales - interpelan, en términos de la rememoración del pasado y la actualización del presente, a las luchas actuales de los movimientos sociales y populares actuales? Por ejemplo, en términos de las luchas contra la dominación de los pueblos originarios, de los esclavos, de las mujeres sometidas, de los obreros inmigrantes anarquistas y trabajadores, de las luchas nacional-populares y antiimperialistas, de las experiencias de autogestión y economía popular, de las luchas por verdad y justicia con relación a los crímenes de las dictaduras recientes, etcétera.

¿Cómo puede interpretarse la aparición en las últimas décadas de fuertes referencias en procesos sociopolíticos y movimientos populares actuales a las luchas de los movimientos liderados por Sandino, Martí, Zapata, Bolívar, Artigas, Zumbí dos Palmares, Tupak Katari, entre otros? ¿Se trata de meras referencias conmemorativas o simbólicas o suponen nuevas concepciones vinculadas a propuestas de rememoración/redención/reparación?

¿Cómo concebir la cuestión del progreso —o de ciertos discursos sobre el desarrollo - presentes en muchas consignas de las fuerzas sociales y políticas de centro-izquierda en la actualidad, incluso en propuestas con contenido revolucionario anticapitalista, en un continente que ha estado atravesado por discursos y prácticas civilizadoras, modernizadoras y conservadoras que no han dejado como saldo, en general, más que desigualdad y violencia? ¿Y cómo pensar esto en un período en el que el capitalismo agudiza sus 
contradicciones y su pérdida de cualquier horizonte civilizatorio, estimulando un "presentismo" igualmente alienante?

¿Qué importancia puede tener la resignificación de la cultura popular, así como de diversas expresiones de la "alta cultura", en nuestros países y para nuestros pueblos en términos de su contribución a una rememoración/ redención colectiva? ¿Cómo podemos entender la cultura, más asociada a formas y modos de vida y de lucha, o a la experiencia auténtica indicada por Benjamin desde la praxis político-cultural de los movimientos sociales y en sus procesos de formación político-cultural articulados a esas luchas?

¿Qué potencialidades puede tener un diálogo entre marxismo y teología en América Latina, que incorpore una interacción como la que plantea Benjamin con el mesianismo judío y el romanticismo revolucionario, donde de hecho ha existido una corriente de diálogo y articulación de la teología de la liberación entre movimientos populares, marxismo y cristianismo de liberación? ¿Cuáles podrían ser algunas de las imágenes dialécticas y constelaciones para dar cuenta de la historicidad y las particularidades de las luchas por la emancipación en nuestras periferias latinoamericanas?

\section{Referencias bibliográficas}

Abensour, M. (2013). Utopiques II. L’homme est un animal utopique. París: Sens \& Tonka.

Abensour, M. (2016). Utopiques III. L'utopie de Thomas More à Walter Benjamin. París: Sens \& Tonka.

Adorno, T. (1995). Sobre Walter Benjamin. Recensiones, artículos, cartas. Madrid: Cátedra.

Agamben, G. (2004). Le temps qui reste. Un commentaire de l'Epître aux romains. París: Payout \& Rivages.

Arendt, H. (2016). Walter Benjamin: 1892-1940. París: Allia.

Benjamin, W. (2005) Tesis sobre la historia y otros fragmentos. Traducción de B. Echeverría. México DF: Contrahistorias.

Benjamin, W. (2006a): Obras. Libro I. Vol. 2. Traducción de Alfredo Brotons, edición original de Tiedemann y Schweppenhaüser con colaboración de Adorno y Scholem. Madrid: Abada.

Benjamin, W. (2006b): Obras. Libro I. Vol. 1. Traducción de Alfredo Brotons, edición original de Tiedemann y Schweppenhaüser con colaboración de Adorno y Scholem. Madrid: Abada. 
Benjamin, W. (2016). Libro de los pasajes. Madrid: Akal.

Bensaïd, D. (1997). Le pari mélancolique. Métamorphoses de la politique, politique des métamorphoses. París: Fayard.

Bensaïd, D. (2010) Walter Benjamin. Sentinelle mesianique. Préface de Enzo Traverso. París: Les Prairies Ordinaires.

Blanqui, A. (2002): La eternidad por los astros. Buenos Aires: Colihue.

Buck-Morss, S. (1995). Dialéctica de la mirada. Walter Benjamin y el Proyecto de los Pasajes. Madrid: La Balsa de la Medusa.

Buck-Morss, S. (2014). Walter Benjamin, escritor revolucionario. Buenos Aires: La Marca.

Coelho, A. (2014). Capitalismo como religião. Uma crítica a sus fundamentos mítico-teológicos [Tesis de doctorado]. San Pablo: Universidade Metodista de São Paulo.

Cohen, E. (ed.) (2015). Walter Benjamin. Resistencias minúsculas. Buenos Aires: Godot.

Dussel, E. (2015). Filosofías del sur. Descolonización y transmodernidad. México DF: Akal.

Echeverría, B. (2010). Siete aproximaciones a Walter Benjamin. Bogotá: Desde Abajo.

Gagnebin, J. M. (2011). História e narração em Walter Benjamin. San Paulo: Perspectiva.

Hinkelammert, F. (2007). Hacia una crítica de la razón mítica. El laberinto de la modernidad. Materiales para la discusión. San José de Costa Rica: Arlekín.

Hinkelammert, F. (2013). La maldición que pesa sobre la ley. Las raíces del pensamiento crítico en Pablo Tarso. San José de Costa Rica: Arlekín.

Konder, L. (1999). Walter Benjamin. O marxismo da melancolia. Río de Janeiro: Civilização Brasileira.

Löwy, M. (2005). Walter Benjamin. Aviso de incendio: uma leitura das teses "Sobre o conceito de história". San Paulo: Boitempo.

Löwy, M. (2010). Juifs hétérodoxes. Romanticisme, messianisme, utopie. París: Editions De L'Eclat.

Löwy, M. (2016). Rédemption et utopie. Le judaïsme libertaire en Europe Centrale: París: Éditions du Sandre. 
Lukács, G. (1985). Historia y conciencia de clase. Vols. 1 y 2. Barcelona: Orbis. Martí, J. (1980). Nuestra América. En J. Martí (1980). Nuestra América. Buenos Aires: Losada, pp. 9-18.

Marx, K. (1969). El dieciocho brumario de Luis Bonaparte. Moscú: Progreso.

Mosès, S. (2006). L'Ange de l'Historie. París: Gallimard.

Münster, A. (1996). Progrès et catastrophe. Walter Benjamin et l'histoire. París: Kimé.

Rosenzweig, F. (1982). L'etoile de la redemption. París: Le Seuil.

Scholem, G. (2003). Walter Benjamin y su ángel. Catorce ensayos y artículos. Buenos Aires: Fondo de Cultura Económica.

Scholem, G. (2007). Walter Benjamin. Historia de una amistad. Barcelona: Random House Mondadori.

Tiedemann, R. (2006). Introducción del editor. En W. Benjamin (2006). Libro de los Pasajes. Madrid: Akal, pp. 9-33.

Traverso, E. (2018). Mélancolie de gauche. La force d'une tradition cachée (XIXe-XXIe siècle). París: La Decouverte.

Vedda, M. (comp.) (2008). Constelaciones dialécticas. Tentativas sobre Walter Benjamin. Buenos Aires: Herramienta.

Witte, B. (1985). Walter Benjamin. Reinbek: Rowolt.

Wohlfarth, I. (2015). Tierra de nadie: sobre "El carácter destructivo" de Walter Benjamin. En E. Cohen (ed.) (2015). Walter Benjamin. Resistencias minúsculas. Buenos Aires: Godot.

Wolin, R. (1982). Walter Benjamin: An aesthetics of redemption. Nueva York: Columbia University Press.

\section{Contribución de autoría}

El trabajo en su totalidad fue realizado por Alejandro Casas. 